\title{
Determinants of Motives for Land Use Decisions at the Margins of the Corn Belt
}

Tong Wang

Assistant Professor and Extension Specialist

Dept. of Economics

South Dakota State University

Contact: tong.wang@sdstate.edu

Moses Luri

Graduate Student

School of Economic Sciences

Washington State University

Contact: moses.luri@wsu.edu

Larry Janssen

Emeritus Professor

Dept. of Economics

South Dakota State University

Contact: Larry.Janssen@sdstate.edu

David A. Hennessy

Professor

Dept. of Agricultural, Food \& Resource Economics

Michigan State University

Contact: hennes64@msu.edu

Hongli Feng

Associate Professor

Dept. of Agricultural, Food \& Resource Economics

Michigan State University

Contact: hennes65@msu.edu

Michael Wimberly

Professor

Dept. of Natural Resource Management

South Dakota State University

Contact: Michael.Wimberly@sdstate.edu

Gaurav Arora 
Graduate Student

Department of Economics

Iowa State University

Contact: gaurav88@iastate.edu 


\title{
Determinants of Motives for Land Use Decisions at the Margins of the Corn Belt
}

\author{
Abstract \\ The extent of United States Great Plains grass agriculture has ebbed and flowed over \\ decades in response to market incentives, government policies, technological \\ innovations and weather patterns. Our thesis is that the land most responsive to these \\ drivers is at the economic margin between grass-based production and cropping. Much \\ of the eastern Dakotas is such an area, primarily under crop-based agriculture \\ although grass remains an important land use. We surveyed land operators in the area \\ on their views about motivators for land use choices. Their views are largely consistent \\ with the economic margin viewpoint. The importance of crop output prices, crop input \\ prices, innovations in cropping equipment and weather patterns on land use decisions \\ grow as one moves north toward the economic margin. Land in more highly sloped \\ areas is more sensitive to crop prices and crop insurance policies. Consistent with \\ human capital theory, older operators are generally less responsive to factors that \\ affect land use. Those renting more land, being more exposed to market forces, are \\ more responsive. As farm size increases, respondents declared higher land use \\ sensitivity to policy issues and technological innovations, suggesting that scale effects \\ render land units more sensitive to land use change drivers. \\ Keywords: cropping systems; ecosystem services; food-fuel-environment debate; \\ grassland conversion; human dimensions to ecosystems.
}




\section{Introduction}

An increase in grassland to cropland conversion in the United States has occurred in recent years. According to Claassen et al. (2011a), much of this conversion has taken place in the Northern Plains. This region, which includes Kansas, Nebraska and the Dakotas, encompasses $18 \%$ of the U.S. rangeland but accounted for $57 \%$ of U.S. rangeland to cropland conversion during 1997 to 2007. Similar findings were reached by Faber et al. (2012), who estimated that between 2008 and 2011, 23.7 million acres of grassland, shrub land and wetlands were converted to cropland across the U.S., with more than 3.2 million acres of habitat removed in the Dakotas alone. Focusing on land cover data from the Western Corn Belt between 2006 and 2011, Wright and Wimberly (2013) concluded that grassland conversion was mostly concentrated in the Dakotas, east of the Missouri River. Lark et al. (2015) imputed that net conversion to cropland during the 2008-2012 interval was 0.21 million acres in North Dakota and 0.53 million acres in South Dakota.

Grassland conversion is associated with many undesirable consequences. Firstly, the resulting loss of habitat has negative consequences for many grassland-dependent species, including North American duck, Sprague’s Pipit and the Dakota Skipper butterfly (Swengel and Swengel, 2015; Lipsey et al., 2015). In addition, grassland is associated with less soil erosion potential than cropland (Pimentel et al., 1995). Conversion to cropland also causes secondary effects such as downstream water pollution, due to increased agrichemical use as well as the elimination of buffers that filter farm runoff (Faber et al., 2012). In addition substantial amounts of stored carbon 
provided by well-managed grassland will be lost upon conversion to cropland (Eve et al., 2002; Gascoigne et al., 2011) and recovery may take decades once the losses occur (Gelfand et al., 2011). Furthermore, soil microorganisms, which are important to the quality of grassland habitat, cannot be readily restored (Johnson, 2000).

Efforts to protect ecosystem services have been diverse. Some have addressed revenue claims that property rights support, rather than the property rights themselves. Commencing with the 1985 Farm Bill, growers found to have drained wetlands are deemed ineligible for certain government farm payments. In that bill highly erodible land was also made ineligible for certain government payments related to crop production unless an environmentally sound land management plan was agreed between operator and the government. However the advent of conservation tillage in conjunction with glyphosate tolerant crop seed has weakened this indirect constraint on cropping (Perry et al., 2016). The 2014 Farm Bill constrained the availability of subsidized crop insurance for those who convert native grassland to cropping. Other interventions have addressed property rights directly, for example a 2015 Environmental Protection Agency ruling that sought to bring many comparatively isolated wetlands under Clean Water Act jurisdiction.

Perhaps the most targeted and extensive interventions have been grassland and wetland easements, which use 'Duck Stamp' hunting fees to buy conservation easements from willing landowners. The Northern Great Plains are predominately privately owned (Hardy Vincent et al., 2014). As a result, land use management decisions, which directly impact the function of land and ecosystem services, are largely made by individual 
landowners (MEA, 2005). These easements are a market-based instrument that separates the right to engage in certain land uses from other property rights (Cooke and Moon, 2015). The U.S. Fish and Wildlife Service administers these easements and has worked with private partners to protect over 340,000 hectares in the area since 1998 (Walker et al., 2013).

Economic returns from different land use options directly affect land use decisions (Rashford et al., 2010), implying that factors which increase cropland profitability prompt farmers to convert to cropland. Candidate factors include rising crop prices, subsidized crop insurance, and improved corn/soybean cultivars. In Minnesota and the Dakotas, for example, high crop prices and rising crop insurance subsidies have been suggested as the main economic factors that contributed to increased conversion rates (Wright and Wimberly, 2013). Motamed et al. (2016) inferred that the advent of ethanol plants expanded corn acreage at the expense of other crops and non-cultivated land use across the greater Cornbelt during 2006-2010 but Arora et al. (2016) found less convincing evidence around specific plants in North and South Dakota. Claassen et al. (2011b) estimated that crop insurance, disaster assistance, and marketing loans contributed to a 2.9 percent increase in cropland acreage between 1998 and 2007 while Miao et al. (2016) arrived at a similar impact. Miao et al. (2015) point out that crop insurance reduced the effective cost of land conversion by stabilizing crop revenues.

Other factors believed to have contributed to land use change include change of ownership structure, technology improvements, the impact of labor requirements, and weather/climate (Reitsma et al., 2015). Land ownership structure in the U.S. is gradually 
evolving, with $40 \%$ of farm land currently under lease (Nickerson et al., 2012; Janssen et al., 2015). Many land units are rented on a short-term basis, which might encourage short-term profits at the expense of long-run sustainability, see Lichtenberg (2007) or Jacoby and Mansuri (2008) for detailed developments on the argument. Technological innovation, such as genetic improvement and improved no-till planters, have also helped to drive the Cornbelt's westward expansion (Clay et al., 2014; Lee et al., 2014). Labor requirements may also prompt land use change as many farmers and ranchers move toward retirement and the land under grazing may be converted for cropping to relieve the workload associated with animal production (Reitsma et al., 2015).

Growing degree days have increased in the area (Travers et al., 2015), allowing for longer season crop varieties but precipitation trends are much less clear (National Climate Assessment, 2014). Wetlands in the area are typically ephemeral or impermanent and the region passes through wet and dry intervals of several years. Wetlands complement grasslands in determining ecosystem productivity because many species, and also therefore their predators, depend on wetlands for food and grasslands for protection. Changing climate will affect ecosystem productivity directly (Withey and van Kooten, 2011) and also through impacts on land use, where research on how climate will affect land use has been very limited.

Despite the growth in research on land use determinants in the area, there are many gaps in the literature. No work that we are aware of has sought to compare the relative importance of these driving forces from the private land owner's perspective. By contrast with the western United States as a whole, in the eastern Dakotas land ownership is 
predominantly in private ownership and private land owners typically makes the land use decision. Moreover, no study has investigated whether farms and farm operators of certain characteristics may view those driving forces differently. Our goal is to better understand motivations for land use choices. In particular we posit and test the claim that the land whose use is most sensitive, as assessed by the owners themselves, to changing market prices, government policies, technical innovation and other factors will be at the edge of the crop-growing region. Based on the analysis of a large survey conducted during Spring 2015, we find that land owner responses largely agree with this marginal view of land use decisions.

In the manuscript's main text we first use standard production theory to provide a conceptual model of how external shocks should affect land use and when responses are likely to be sensitive. We infer that land will be most sensitive to shocks in locations where grass uses and crop uses are comparably rewarding. Based on the model we view land owner declarations on the relative importance of land use drivers to be the objects of interest. If these self-declared land use motivations vary in a manner that is consistent with land use decisions as predicted by our model then we have evidence in favor of the margin-is-most-competitive thesis. Furthermore, we would not need to infer motivation for land use change through correlating variation in land use actions with variation in potentially causal variables. This is because consciously-given direct evidence has been provided by the decision-maker. Our conceptual model is followed by descriptions of survey design and administration, and of the data collected. The econometric tools used are then explained, followed by a presentation and discussion of results. A discussion 
section concludes.

\section{Conceptual Model}

Claassen et al. (2001b) have proposed a model in which profitability under cropping less that under grass agriculture is an increasing function of land quality. The crops and grass profit curves in Figure 1 reproduce the essence of their Figure 9. A representative farmer's land quality density function is also provided. The margin is where the profit curves intersect. If only profitability considerations matter then the area under the density curve but left of the land quality level at which the curves intersect will be under grass. When the mass density of land in the neighborhood of this cut-off point is large then the land use choice will be sensitive to factors that affect grass and crop profitability.

Suppose that land tract $i$ has two alternative land uses, cultivated cropping and grass. Producer utility from cultivated cropping is given as $\eta_{i}^{c}+\pi_{i}^{c}$ where $\pi_{i}^{c}$ is profit from cropping and $\eta_{i}^{c}$ reflects taste and profit idiosyncrasies particular to a cropping operation. Profit from cropping is obtained as $\pi_{i}^{c}\left(p^{c}, r^{c}, \theta^{c}, w\right)=\max _{x_{i}^{c}} p^{c} q_{i}^{c}\left(x^{c} ; \theta^{c}, w\right)-r^{c} x_{i}^{c}$ where $p^{c}$ stands for output price, $x^{c}$ is a vector of cropping inputs with price vector $r^{c}$, and $\theta^{c}$ can be viewed as a technology innovation index or a soil quality index. Variable $w$ represents weather/climate variables, and a higher value of $w$ stands for more rainfall in arid areas, less heat in hot areas, etc. The dual output function is written as $q^{c, *}\left(p^{c}, r^{c}, \theta^{c}, w\right)$ where $d q^{c, *}\left(p^{c}, r^{c}, \theta^{c}, w\right) / d \theta^{c} \geq 0$ and $d q^{c, *}\left(p^{c}, r^{c}, \theta^{c}, w\right) / d w \geq 0$ are 
assumed. Producer utility from grass-based production is given similarly, i.e., with $\eta_{i}^{g}+\pi_{i}^{g}$ as producer utility and profit as $\pi_{i}^{g}\left(p^{g}, r^{g}, \theta^{g}, w\right)=\max _{x^{g}} p^{g} q_{i}^{g}\left(x^{g} ; \theta^{g}, w\right)-r^{g} x_{i}^{g}$ where variables have meanings that correspond to those for cropping. The profit maximizing producer seeks to maximize over land choice alternatives, i.e., $\max \left[\eta_{i}^{c}+\pi_{i}^{c}\left(p^{c}, r^{c}, \theta^{c}, w\right), \eta_{i}^{g}+\pi_{i}^{g}\left(p^{g}, r^{g}, \theta^{g}, w\right)\right]$

Before investigating the origins of declared motivations for land use change we will place further structure on random contributions to each profit level. Following McFadden (1974), we assume that these idiosyncrasies follow the extreme-value distributions such that the standard logit probabilities emerge from choice problem (1) when integrated over idiosyncrasies. The probability that a land unit is under crops is then

$\operatorname{Pr}(\mathrm{cr})=\frac{e^{\lambda \pi_{i}^{c}\left(p^{c}, r^{c}, \theta^{c}, w\right)}}{e^{\lambda \pi_{i}^{c}\left(p^{c}, r^{c}, \theta^{c}, w\right)}+e^{\lambda \pi_{i}^{g}\left(p^{g}, r^{8}, \theta^{\beta}, w\right)}}$

where $\lambda$ is a positive constant. The land unit is under grass with probability $\operatorname{Pr}(\mathrm{gr})=1-\operatorname{Pr}(\mathrm{cr})$. Eqn. (2) may be viewed in two ways. One is as a true probability, from the viewpoint of someone who does not observe farm-level idiosyncrasies, that the land will be cropped. The other is as the share of land that will be cropped on a given farm so that the integration over idiosyncratic randomness occurs at the plot level and not at the farm level. Although the distinction is moot at the aggregated regional level, the latter interpretation is more realistic for our context as most farmers in the area engage in both grass-based agriculture and cultivated crop production.

Crop prices in the United States and throughout much of the world increased 
dramatically between 2006 and 2013 before settling at lower, though historically high, levels through 2016. In Spring 2015, when our survey was completed, Chicago-traded corn futures prices were at about $\$ 3.75$ per bushel, more than $70 \%$ above the average price between 2000 and 2006. The impact of a change in crop price on land use decisions can be gauged through how responsive the cropped land probability, or share, is to crop price, or, upon some algebra,

$$
\frac{d \operatorname{Pr}(\mathrm{cr})}{d p^{c}}=\lambda q^{c, *}\left(p^{c}, r^{c}, \theta^{c}, w\right) \operatorname{Pr}(\mathrm{cr}) \operatorname{Pr}(\mathrm{gr}) .
$$

Thus the response rate vanishes under two conditions; when all land is cropped and when none is cropped. The response should vanish at the extremes but be positive in between, where the fraction of land marginal to either use is positive. Figure 2 illustrates. The figure includes two graphs. One, with axis on the right, graphs the quadratic relationship $y(\operatorname{Pr}(\mathrm{cr}))=\operatorname{Pr}(\mathrm{cr}) \operatorname{Pr}(\mathrm{gr})=\operatorname{Pr}(\mathrm{cr})-[\operatorname{Pr}(\mathrm{cr})]^{2}$. Of course $y(0)=y(1)=0$. The other graph, with axis on the left, depicts $d \operatorname{Pr}(\mathrm{cr}) / d p$.

We turn now to where sensitivity is likely to be greatest. Note first that, as functions are assumed to be continuous, $d \operatorname{Pr}(\mathrm{cr}) / d p^{c}$ has a maximum somewhere on $\operatorname{Pr}(\mathrm{cr}) \in(0,1)$. Differentiating (3) once more we have

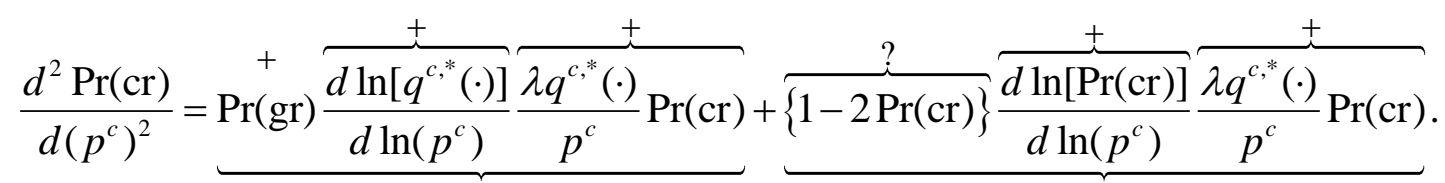

$$
\text { Intensive margin effect, IME }
$$

$$
\text { Extensive margin effect, EME }
$$

The first right-hand term, labeled IME, captures the intensive margin component of supply response, or price elasticity of supply with respect to crop yield, holding land use constant. This effect occurs as a result of increased use of fertilizer, pesticide, and 
available technology. The second right-hand term, labeled EME, is the extensive margin component of supply response, or price elasticity through land use conversion. From Eqn. (4) we know that $\operatorname{Pr}(\mathrm{cr})$ is certainly convex in $p^{c}$ when the crop share is no more than $50 \%$ but could be either concave or convex when the crop share exceeds $50 \%$.

So as to shed perspective on what (3)-(4) can relate for the eastern Dakotas, Figure 3 provides data on average crop shares in respondents' land operations. Yellow represents $85 \%$ or more cropping, darkest green represents primarily grass and lighter shades of green represent more intensive cropping operations. Generally grass becomes more prevalent toward the west. A north-south pattern is less discernible in part because of significant cropping along the eastern columns of counties in North Dakota that contain and abut the fertile Red River Valley, e.g., Griggs, Steele, Traill, Barnes, Cass and Richland counties. The valley defines much of North Dakota's border with Minnesota. Equations (4) suggest that land use response to crop prices should be greatest toward the west, where $\operatorname{Pr}(\mathrm{cr}) \approx 0.5$ in the line of counties commencing in Burleigh and moving South-southeast to Charles Mix. The effects of input prices and policy instruments can be studied similarly. In all cases we expect sensitivity to be greatest when more land is at the margin, i.e., when $\pi_{i}^{c}(\cdot) \approx \pi_{i}^{g}(\cdot)$.

Hypothesis 1: All else equal, as we progress north and west across the region away from the Corn Belt then land use responsiveness to prices and policies that promote cropping should increase.

Next we consider how technical innovation that promote cropping or soil quality can 
affect the share of all land that is cropped. The technology at issue could include seed technology developments, such as drought tolerant seed, Technology could also include pest management innovations, improved crop yields and more efficient crop equipment, which we will discuss shortly afterwards. Soil quality could reflect soil depth or land slope. Similar to (3) above,

$$
\frac{d \operatorname{Pr}(\mathrm{cr})}{d \theta^{c}}=p^{c} \operatorname{Pr}(\mathrm{cr}) \operatorname{Pr}(\mathrm{gr}) \frac{d q^{c, *}(\cdot)}{d \theta^{c}} .
$$

Once again, the response should be largest when $\operatorname{Pr}(\mathrm{cr}) \operatorname{Pr}(\mathrm{gr})$ is largest, i.e., around about when cropping takes up 50 percent of agricultural land.

Hypothesis 2: As we progress north and west across the region away from the Corn Belt then land use responsiveness to technology innovations such as improved crop yields and more efficient crop equipment and soil quality traits should increase.

Turning to pest management, the argument has been made that areas where a crop or cropping system is widely adopted provide pests with the opportunity to thrive. The reasoning is that a pest has the opportunity to find refuge elsewhere when pesticide is applied on a particular area, and also widespread use of pesticides in an area may kill a pest's predators (Meehan et al., 2011, 2015). Consistently positive relationship have been found over the years between pest abundance and landscape simplicity, where the latter is partly characterized by the proportion of a county that is occupied by harvested cropland (Meehan et al., 2011, 2015). As indicated on Figure 3, cropland proportion decreased gradually from the east to the west. Therefore as we move west across the 
surveyed region, the pest issue should become less severe and the pest management innovation will receive less attention. However, this trend may not be distinguishable as we move northward as no clear spatial trend exists in the proportion of cropland as one moves north.

Hypothesis 3: As we progress west across the region away from the Corn Belt then land use responsiveness to pest management innovations should decrease.

Drought tolerant seed is likely to be in greater demand when moving from the Corn Belt towards the west, due to lower average precipitation and increased vulnerability to drought (Wright and Wimberly, 2013). Furthermore, when moving south within our study area, an implication of increased temperature is that more water is lost through evapotranspiration. For this reason the benefits from drought tolerant seed should be more apparent as one moves south.

Hypothesis 4: As we progress south and west across the region then land use responsiveness to drought tolerant seed innovations should decrease.

We turn now to the effect of weather metrics on land use responsiveness. Our interest here is motivated by the belief that climate change in the area's eastern portions may lead to the warmer, wetter growing environment that favors corn (National Climate Assessment, 2014). ${ }^{1}$ The relevant derivative is:

\footnotetext{
${ }^{1}$ Unpublished work by Gaurav Arora, gaurav88@iastate.edu, at Iowa State University provides evidence that corn and soybean would generally benefit from warmer, wetter
} 
$\frac{d \operatorname{Pr}(\mathrm{cr})}{d w}=\left\{p^{c} q^{c, *}(\cdot) \frac{d \ln \left[q^{c, *}(\cdot)\right]}{d \ln (w)}-p^{g} q^{g, *}(\cdot) \frac{d \ln \left[q^{g, *}(\cdot)\right]}{d \ln (w)}\right\} w \operatorname{Pr}(\mathrm{cr}) \operatorname{Pr}(\mathrm{gr})$

As with land quality in Figure 1, we assume that crop yield is more sensitive to weather than is the yield of deep-rooted perennial grass so that we expect $p^{c} d q^{c,{ }^{*}}(\cdot) / d w \geq p^{g} d q^{g, *}(\cdot) / d w$.

Hypothesis 5: As we progress north and west across the region away from the Corn Belt and into less amenable climate zones then land use responsiveness to changing weather/climate patterns should increase.

Next, while wildlife issues may not be the most important factor for land use change decisions, we hypothesize that the impact of wildlife habitat on land use responsiveness is greater for those producers who are in closer proximity to wildlife habitat. Moving away from the Corn Belt region towards the west, the proportion of grassland increases (Figure 2). The amount of grassland cover bordering wetlands is very important for the survival of duck species (Wright and Wimberly, 2013). Therefore, when moving towards the west of the studied region we expect that more producers consider the impact to wildlife habitat when making land use decisions.

Hypothesis 6: As we progress west across the region away from the Corn Belt then land use responsiveness to wildlife habitat should decrease.

Having modeled the general effects of prices and policies, technology, climate and wildlife, we turn now to incentives for human capital formation. Investment in new weather in the eastern Dakotas. Data used were NASS county average historical yields and local weather station records 1950-2013. 
technology typically includes human and physical capital components. Returns on investment in reduced tillage and precision agriculture equipment will accrue in the longer-run. Apart from a possibly lower willingness to entertain new investments into changing the production system from grass to crop, older farmers might also foresee a limited time horizon over which to recoup such investments. Even if the farmer intends to hand over the enterprise to a family successor, skills required to manage a more cropintensive farm may transfer only imperfectly to the successor. For whatever reasons, older farmers are found to be, generally, less inclined toward adopting newer technologies and adapting to altered decision environments (Zepeda, 1990; Huffman and Mercier, 1991).

Hypothesis 7: Land use response to external market and policy factors should decrease as respondent age increases.

The ownership composition of land farmed may also impact declared responsiveness to external factors. For a variety of reasons, much land in the area is not owned by the operator. In comparison with owner-operators, tenant operators likely face different economic and social incentives when operating that land. Acreage that is rented in as a share of acreage operated by a farm unit could conceivably have many implications for motivation, even when making decisions for the portion of operated land that is owned. Feder et al. (1985) provide an extensive review of issues regarding operator choices and tenancy status. A common view is that those who rent in more land may be credit constrained and/or risk vulnerable. This may influence them away from making risky 
investments intended to adapt their operations for a changed production environment. However, subsidized crop insurance as well as other government underwritten risk management tools have long been available to farm operators and many question whether much financial risk remains in crop production (Babcock and Hart, 2004). An alternative view is that operators who rent in land have rental charges to pay. For this reason they are more likely to subordinate personal preferences over cropping choices and choose the more commercially profitable choices, i.e., to be more responsive to market forces. As explained below, we lean more toward the latter than the former perspective.

Modern crop cultivation methods save operator time and take advantage of opportune time windows by quickly covering extensive areas. These machines are large and expensive, so that the producer needs to spread machinery costs over large tracts of proximate acres. Land operators who own inadequate land to make a living and who respond by renting in may not wish to operate an intensively leveraged tillage system. However they will compete in rental markets with those who operate that way and so they may feel compelled to do so in order to remain viable.

Hypothesis 8: All else equal, those who rent in more land should crop more and also be more responsive to crop output and input prices than those who rent in less land.

Having developed our hypotheses we turn to describing the data that we will use to test them. 


\section{Survey Description}

The study area is located in the Prairie Pothole Region of the Dakotas where corn and soybeans are now the dominant cropland use and where there has been moderate to extensive land use conversion activity from 2004 to 2015. Our study includes 37 counties in South Dakota and 20 counties in North Dakota. Further details are provided in Figure 3. As depicted, all but one of the surveyed farms are located on the east side of either South Dakota or North Dakota. ${ }^{2}$ The map also shows that cropland acres comprise a majority of all farmland acres in most of these counties. The sample frame was targeted at farmers that operated at least 100 acres and, in recent years, raised one or more among wheat, corn, soybeans or grass/hay. The sample was purchased from the highest quality farm sampling frame made available by Survey Sampling International (SSI), see https://www.surveysampling.com/. Sample selection was proportional by county so that counties with comparatively more eligible farms would have more farmers included.

A total of 3,000 farm operators in the study region were randomly selected. All survey mailing and data coding tasks were handled by Iowa State University's Survey Research Center. The collection period was from early March to early May 2015 and involved two mailings with a postcard reminder in mid-March. Each farmer/rancher received an eight page questionnaire consisting of several sections including information requests about their cropping systems, land use and cropping decisions from 2004 to 2014, along with data on their farm business and operator characteristics.

${ }^{2}$ The Stanley County farm was obtained from a respondent who we believed to farm east of the Missouri River but who declared that most acres farmed were in that county. 
The survey instrument is available in Luri (2015).

The eligible sample was 2,797 producer households as some households in the frame were no longer operating a farm or ranch in the study region. The average response rate was $40.0 \%$ in South Dakota, which was higher than the $31.4 \%$ average response rate in North Dakota. Across different regions where the survey was conducted, the response rate varied from 30.1\% in Central North Dakota to 43.7\% in North East South Dakota. The overall useable response rate was $36.7 \%$ (1,026 of 2,797) of producers sampled. For the study region, the average operated farm size per respondent was 1,686 total acres with 1,206 cropland acres. Most of the remaining acres were in Conservation Reserve Program or pasture/range use. Average farm size (measured by both total acres operated and cropland acres) was higher in North Dakota counties and in the North Central South Dakota region.

Two approaches were used to assess the 'representativeness' of survey respondents to the study region's general farm operator population. First, selected characteristics of respondent farm operations were compared with available data for non-respondent operations included in the eligible sample of producers. Average acres operated by respondents was 10-15\% smaller than by non-respondents in terms of crop acres planted, corn acres, and soybean acres. These differences in means were statistically significant at the 0.01 probability level. However, there were no statistically significant differences in wheat acres, hay acres, or beef cow herd size.

The second approach was to compare respondent farm operator and selected farm business characteristics with farm operator/business data in the 2012 Census of 
Agriculture. Overall, the survey respondents are most representative of:

- Full-time farm operators with no off-farm work, no non-farm business income and not retired (87\% of respondents);

- Farm operations with $\$ 50,000$ or more gross farm sales (96\% of respondents); and

- Farms with 260 or more acres operated (94\% of respondents) where $77 \%$ operated between 500 to 5,000 acres.

Farmers with these characteristics operate more than $85 \%$ of farmland acres in the region.

\section{Data Description}

Our interest lies in understanding the relative importance that survey respondents place on different factors which affect agricultural land use decisions, and in how relative importance changes with operator and farm characteristics. The independent variables in our regression are measures of relative importance assignments that respondents declare for different land use decision motives. We divide factors under scrutiny into three broad categories; 1) price and policy issues, the list being changing crop prices $\left(Y_{1}\right)$, changing input prices $\left(Y_{2}\right)$, availability of crop insurance policies $\left(Y_{3}\right)$ and labor availability $\left(Y_{4}\right) ; 2$ ) technology issues, specifically availability of drought tolerant seed $\left(Y_{5}\right)$, development of pest management practices $\left(Y_{6}\right)$, crop yield improvement $\left(Y_{7}\right)$ and development of more efficient crop equipment $\left(Y_{8}\right)$; and 3) environmental issues, i.e., improving wildlife habitat $\left(Y_{9}\right)$ and changing weather/climate 
patterns $\left(Y_{10}\right)$. These variables are summarized in Table 1.

As indicated in Table 2, there are generally three different levels of farmers' responses to these issues: 1) low impact (value $=1$ ), meaning that the issue being asked is declared to have either 'no impact' or 'slight impact' on the respondent's land use decisions; 2) medium impact (value = 2), meaning that the issue is asserted to have 'some impact'; and 3) high impact (value = 3), meaning that the issue has 'quite a bit of impact' or 'great impact' on land use decisions.

Several survey questions solicited data on farm operator characteristics, including their age, gender and highest level of education. However, only 24 female operators responded so we do not use this variable in our analysis. In addition, the highest level of education variable was not found to impact land use decisions in a significant manner and so was omitted from the equations that we present here. Age was divided into five distinct categories, with discrete numbers 1 to 5 denoting age ranges 19-34, 35-49, 50-59, $60-69$ and $\geq 70$ respectively.

Explanatory variables that determine the land use decisions are farm location (latitude and longitude of the respondent's address), soil quality, slope, farm size, and land tenancy status. Location determines weather endowments, where average annual temperature declines by about 4 degrees centigrade as one moves north and average annual precipitation declines by about 250 millimeters (30-40\%) as one moves west across the study region. Location also determines transportation costs and access to markets such that grain prices are generally lower as one moves north and west. The preponderant use of grains in the area has been for livestock and human consumption 
to the south and east in the United States and in international markets via the Mississippi Waterway. Finally, agglomeration spillovers in the vicinity of population centers can reduce farm operation marketing, input procurement and financing costs. The main population centers in the study are to the east.

The location information of our survey respondents was provided by Iowa State University Survey Research Center from the SSI database of sampled farms after the survey was completed. We do not know for sure that this address is proximate to the land farmed but our preliminary analyses lead us to believe that address location is near the farm/ranch land operated. As Table 2 shows, latitudes of surveyed farms ranges from 42.91 to 47.83 degrees North $(0=$ Equator), while longitude ranges from 96.47 to 100.79 degrees West.

The U.S. Department of Agriculture Natural Resource Conservation Service (NRCS) land capability classification (LCC) system, which is based on the severity of limitations for crop production, was used to proxy soil quality. Classes I and II soils have few limitations and are typically cropped intensively, while Class III soils have moderate limitations for crop production. Class IV soils are very marginal for crop production while Class V-VIII soils are seldom cropped. In this study, soil quality of the farm and adjacent land was defined as the percentage of marginal crop land, or percentage of soils with LCC equal to IV within 1 mile radius of the farm's location. We chose a onemile radius because we wish to appropriately indicate the extent of marginal land in the farm's vicinity. Slope of land in the area was measured as the percentage of soils with slope less than or equal to 3 within 1 mile radius. Slope less than $3 \%$ was used as a proxy 
for non-HEL (highly erodible land) and better quality cropland. Slope and land class data with geographic coordinates were obtained from the NRCS SSURGO. ${ }^{3}$

Farm size and tenancy status observations were from farmers' survey responses. Farm size denoted total farm acres that the farmers operated in 2014, which included cropland, CRP land and pasture/rangeland. Ownership of the land was a discrete choice variable where ' 1 ' = 'owning all operated acres', '2' = 'owning most operated acres', '3'= 'owning about half of operated acres', '4’ = 'renting most operated acres', and '5’ = 'renting all operated acres.' Therefore, a larger number indicates that a larger fraction of operated land is being rented in. The typical respondent was closer to 'owning about half than 'owning most' land operated.

Another important farm operator characteristic is the percentage of operated land that is under crops, calculated as the proportion of cropland acres divided by total farm acres. Based on the cropland percentage we divide farmers into three different groups. Operators with less than 50 percent of land under crops are classified as low crop intensity (LCI) while operators with more than 90 percent of land under crops are classified as high crop intensity (HCI). Intermediate farmers are categorized as medium crop intensity (MCI). Of 1,026 respondents, 246 (24\%), 402 (39\%) and $378(37 \%)$ belonged, respectively, to the LCI, MCI and HCI categories. Figures 4 (a)-(c) characterize group-wise farmer responses to different factors that might affect how they used their agricultural land. As the groups are not perfectly balanced in Figure 4 we compared percentages of farmers, rather than numbers of farmers, that made different responses.

\footnotetext{
${ }^{3}$ Details are available at http://www.nrcs.usda.gov/wps/portal/nrcs/detail/soils/survey/geo/?cid=nrcs142p2_053627
} 
Figure 4(a) clearly indicates that output prices, or changing crop prices $\left(Y_{1}\right)$ is associated with the highest proportion in the 'high impact' category. This finding was consistent for farmers in all groups. Not surprisingly, HCI group farmers typically regard changing crop prices as of higher significance. For example, 55\% of HCI group operators reported that crop prices had a high impact on their land use decisions while, only $43 \%$ and $38 \%$ gave that response among MCI and LCI groups. Other than crop prices, input market prices $\left(Y_{2}\right)$ and improved crop yields $\left(Y_{7}\right)$ were generally regarded as the next most important influences on land use decisions, followed by the development of more efficient cropping equipment $\left(Y_{8}\right)$. Consistent with our expectation, these three issues were found to be relatively more important to HCI group operators.

When compared with other groups, changing climate patterns $\left(Y_{10}\right)$ were also regarded as more important by HCI group operators. This might be because crop yields are more likely to fluctuate with changing weather, while the performance of resilient deep rooted perennial grass is more robust to different climate conditions. Similar to the impact of changing climate patterns were availability of crop insurance policies $\left(Y_{3}\right)$ and developments in pest management practices $\left(Y_{6}\right)$. Again, these two issues are of direct relevance to the cropland so we expected to find more high-impact responses among the HCI group.

Regarding wildlife habitat, $13 \%, 9 \%$ and $7 \%$ of farmers in the respective LCI, MCI and HCI groups chose the high-impact category. These responses suggest that land 
operators with a larger grass fraction are more willing to take wildlife habitat improvement into consideration when making land use choices. This may be because ranch-focused operators are generally more aware of wildlife habitat loss. Alternatively, farmers who are more interested in preserving wildlife habitat may be less likely to have converted from grassland to cropland in the past.

Of all the listed issues, availability of drought-tolerant seed $\left(Y_{5}\right)$ and improving wildlife habitat $\left(Y_{9}\right)$ were the only two that were more likely chosen as of higher impact by farmers in the LCI group. These results may reflect the tendency for farmers with lower cropland percentages to be located in areas with less rainfall, so that the availability of drought-tolerant seed is more pertinent.

The geographic bias that our preliminary analysis identifies highlights the need for a more controlled approach toward analysis. The ordinal regression approach that we take is explained in the next section.

\section{Ordinal Logistic Regression}

In the survey, farmers' responses take values that have an intrinsic order and enable us to apply the ordinal logistic regression model. We label 'low impact' as ' 1 ', 'medium impact' as '2' and 'high impact' as ' 3 '. Denoting the observation number by $i$ and the number of explanatory variables by $p$, we write the vector of explanatory variables as $\left(x_{i 1}, x_{i 2}, \ldots, x_{i p}\right)$. Define $\tau_{i j}=\operatorname{Pr}\left(Y_{i}=j\right)$ for $j \in\{1,2,3\}$. As we choose to model the probability of choosing a higher degree of impact, the cumulative probability is defined as $\varphi_{i j}=\operatorname{Pr}\left(Y_{i} \geq j\right)$. Specify $\varphi_{i 3}=\operatorname{Pr}\left(Y_{i} \geq 3\right)=\tau_{i 3}, \varphi_{i 2}=\operatorname{Pr}\left(Y_{i} \geq 2\right)=\tau_{i 2}+\tau_{i 3}$, and 
$\varphi_{i 1}=\operatorname{Pr}\left(Y_{i} \geq 1\right)=1$. Clearly the cumulative probability function increases as response value $j$ decrease.

Define the cumulative logit link as $\operatorname{logit}\left(\varphi_{i 3}\right)=\log \left[\tau_{i 3} /\left(\tau_{i 1}+\tau_{i 2}\right)\right]$ and $\operatorname{logit}\left(\varphi_{i 2}\right)=$ $\log \left[\left(\tau_{i 2}+\tau_{i 3}\right) / \tau_{i 1}\right]$. The proportional odds model is specified as:

$$
\begin{aligned}
& \operatorname{logit}\left(\varphi_{i 2}\right)=\alpha_{2}+\beta_{1} x_{i 1}+\beta_{2} x_{i 2}+\cdots+\beta_{p} x_{i p} ; \\
& \operatorname{logit}\left(\varphi_{i 3}\right)=\alpha_{3}+\beta_{1} x_{i 1}+\beta_{2} x_{i 2}+\cdots+\beta_{p} x_{i p} .
\end{aligned}
$$

If other variables are fixed at 0 , then $\alpha_{3}$ represents the $\log$ odds of choosing $Y_{i}=3$ instead of $Y_{i} \in\{1,2\}$ while $\alpha_{2}$ represents the log odds of choosing $Y_{i} \in\{2,3\}$ instead of $Y_{i}=1$. The model assumes that the cut points, in our case either 1,2 or 3 , do not affect the odds. An implication is that coefficients for different functions are held to be the same across regressions in system (7) and only the intercept term differs. These crossequation restrictions have been imposed in system (7). When compared with the multinomial logit regression model, the proportional odds model is more parsimonious in that fewer coefficients are estimated.

\section{Regression Results}

To address endogeneity concerns we use variables over which the landowner has little influence. Two pertain to land quality, slope and pc_lcc4_1m as explained in Table 1. Operator location, as given by the latitude and longitude of the respondent's address, also determine land productivity through weather endowments, proximity to market and infrastructure availability. These four variables represent geographic endowments 
as determinants of land use choice. Operator age is also included to represent human capital and life-cycle related preferences. Farm size and tenancy status are included to ascertain roles for control over land assets on the relative importance ascribed to different factors. While these control variables are partly determined by land owners, they are also outcomes from events that are largely outside their control; including presence of siblings and interest in farming/ranching among siblings. When taken together these variables can be thought of as exogenous determinants of the relative importance attached to our menu of factors.

Table 3 presents the estimation results for price and policy queries. We can see that four variables significantly affected the impact of changing crop prices $\left(Y_{1}\right)$ in land use management decisions; land slope, tenancy status, farmer's age, and latitude. For example, given all other variables fixed, when land with slope $\leq 3$ within a one mile radius increased by one percent, then the $\log$ odds for $Y_{1}=3$ vs. $Y_{1} \in\{1,2\}$ and the log odds for $Y_{1} \in\{2,3\}$ vs. $Y_{1}=1$ increased by 0.003 . In other words, for farmers located on less hilly landscapes the issue of changing crop prices was more likely of greater importance. In addition, farmers tend to place more value on both changing crop prices $\left(Y_{1}\right)$ and changing input prices $\left(Y_{2}\right)$ when they rent in more of the land, when they are younger and are located further north. The table provides support for Hypothesis 1 in the sense that land units at higher latitudes, and closer to the 50\%-50\% crop to grass interface, are more sensitive to crop output and input prices. But we find no support for the hypothesis in the longitude dimension. We do find support for Hypothesis 7 in that older land owners are less responsive to market prices than are their younger peers. 
Hypothesis 8 also finds support in the table as declared sensitivity to market prices increases with tenancy status. Thus the table provides evidence in favor of the notion that tenants are more likely to have their nose to the grindstone and so feel compelled to place more weight on prices as land use determinants.

Regarding the availability of crop insurance policies $\left(Y_{3}\right)$, farm size became significant. According to Table 3, when farm size increases by 1,000 acres, the log odds of $Y_{3}=3$ vs. $Y_{3} \in\{1,2\}$ and the $\log$ odds for $Y_{3} \in\{2,3\}$ vs. $Y_{3}=1$ increases by 0.081 . Land slope is also a significant variable, implying that for farms located on steeper slopes then land use management decisions are less likely to be affected by the availability of crop insurance policies. Such land is less likely to be under crops that receive the largest subsidies in dollar terms.

Labor availability $\left(Y_{4}\right)$ seems to be more of a concern on larger farms, perhaps because such farms are more likely to hire in labor. As farm size increases by 1,000 acres, the log odds of $Y_{4}$ being of higher impact increases by 0.14 . It also appears that availability was a bigger constraint in land use management decisions for younger farmers and for more northerly farms. Due largely to growth in the natural gas sector, North Dakota markets for labor skilled in the use of heavy machinery was very tight during 2006-2014 (Job Service North Dakota, 2014).

Regression results on technology queries are provided in Table 4. Consistent with Hypothesis 4, respondents located further south or west declared the availability of drought tolerant seed $\left(Y_{5}\right)$ to be more important. Average annual rainfall level drops as 
we move west from the Cornbelt while the south encounters higher water loss through evapotranspiration. In addition, when marginal land type, or the percentage of soils with LCC equal to 4, increases then the role of drought tolerant seed weakens slightly. This is the only regression where marginal land type is significant, though at the $10 \%$ level.

Regarding the development of pest management practices $\left(Y_{6}\right)$, farm size was significant, as the $\log$ odds of $Y_{5}=3$ vs. $Y_{5} \in\{1,2\}$; and the $\log$ odds for $Y_{5} \in\{2,3\}$ vs. $Y_{5}=1$ increased by 0.079 when farm size increased by 1,000 acres. Conservation and reduced tillage have been promoted by the availability of herbicide tolerant seeds (Perry et al., 2016), but require investments in different machinery and technical knowledge that provide opportunities for scale economies and so favor larger operations. Longitude also matters. Consistent with Hypothesis 3 and with the landscape simplification argument articulated in Meehan et al. (2011, 2015), farms located further east care more about pest management practices. For improved crop yields $\left(Y_{7}\right)$, the only variable found to be significant is farm size. We do not have an explanation for this relationship, though it is not inconsistent with our prior beliefs. We were not surprised to find that farm size also matters for determining the relative importance of how the advent of more efficient cropping equipment $\left(Y_{8}\right)$ has affected land use. Again, larger farms are likely better positioned to take advantage of such innovations. Furthermore, and in accord with Hypothesis 2, the role that innovations in cropping equipment was declared to have played in land use decision making was larger toward the north.

Finally, Table 5 presents regression results on environmental issues. For farm 
operators located further west, improving wildlife habitat $\left(Y_{9}\right)$ was more likely to be a declared factor in determining land use. This may be because more land is under grass toward the west and producers find self-validation in appreciating environmental outputs from their land. A distinct conjecture is that they are more aware of wildlife, a form of availability bias (Kahneman, 2011). Self-selection may also be at play in that among two siblings in a pastoral area the more pastorally inclined stayed to operate the land while a technologically oriented sibling may see more opportunities for expression in a cropping area. Regarding the impact of changing weather/climate patterns $\left(Y_{10}\right)$, its $\log$ odds increased when land slope $\leq 3$ within one mile radius increased by one percent, and when latitude increased by 1 degree. These responses are consistent with Hypothesis 5 and Hypothesis 6.

\section{Discussion}

Our model is one in which land use is shaped by land use change motives which are, in turn, formed by more primitive variables that are largely geographic and can be taken as exogenous to the operator. Table 6 summarizes how our findings compare with the hypotheses that we posed.

Although motives are intermediate in our model, we take time here to say a bit more about some topical survey findings in this regard. Survey results suggest that while climate change may affect land use change decision making, it is probably not the most important driver, especially for farmers located toward the south in our study region. Other factors such as output/input prices, improved crop yields and more efficient crop 
equipment are likely to play more important roles. Consistent with our finding, Reilly et al. (2003) also concluded that non-climatic forces have likely dominated the north and westward movement of crops. For example, Rosenberg (1992) attribute the northward movement of corn production to factors such as changes in cultivation technology, the introduction of corn hybrids, and economic incentives rather than as a result of climate change. Huffman and Evenson (1993) assert that the northern movement of soybean was largely due to new varieties adapted to longer summer days.

Our results showed that younger operators as well as those who leased more land generally care more about prices. The age and tenancy status variables are negatively correlated. Younger farmers typically lease more of the land that they operate while older farmers concentrate more on the land they own (Hoppe et al., 1995). Previous research results also indicated that land ownership is an important factor in farmers' land use decisions. Bills (1985) has observed that half of owner-operated land was grassland while nearly two-thirds of rented land was planted in row crops. Rather than causal, this propensity may be due to greater ease of exchange in rental markets for cropland than for grassland. Tenancy and part-ownership are growing trends in United States land markets. Soule et al. (2000) and others have found that, when compared to land owners, cash-renters are less likely to use conservation tillage and other practices that provide ecosystem benefits over the long term. This set of findings, while not entirely settled (see, e.g., Varble et al. (2016)), does suggest that land use may become more sensitive to commodity output and input prices in the years to come.

Consistent with our survey finding, the literature also suggests how crop insurance 
may affect land use conversion decisions. As crop insurance covers large losses, it provides farmers with incentives to plant in areas and on soils that are not well-suited to crop production (USGAO, 2007; Feng et al., 2013). In addition, innovations in cropping equipment can also prompt land use conversion. Compared to conventional tillage, notill can substantially reduce soil erosion (Lindstrom et al., 1994) and thus provide an option to meet the "sodbuster" provision in U.S. agricultural income support policy (Claassen et al., 2011b). Our results demonstrate that larger operators place a higher value on both crop insurance and efficient crop equipment than those operating fewer acres. In other words, the survey provides evidence that the availability of crop insurance and crop equipment innovations are more important for the large operators whose decisions weigh more on landscape structure than they are for smaller operators.

Our finding hold that, among other issues, wildlife habitat loss receives least weight as a motivator when making land use decisions, especially for farmers located further east. As far as we are aware, our paper is the first to point out that priority issues for farmers in land use conversion decisions vary by their location. For example, attributes connected with longitude play important roles in determining the emphasis that drought tolerant seed and pest management practices have as land use determinants. The availability of drought tolerant seed facilitates land use change for farmers located in the west, while farmers located in the east benefit more from enhanced management practices.

\section{Concluding Remarks}


The paper's main thesis is that land which is marginal between crop and grass uses will be most sensitive to factors that determine cropland profitability. Our analysis provides strong, though sometimes nuanced, support for this hypothesis. In particular, latitudinal location, operation size, tenancy/ownership status and land slope are found to strongly influence several declared motives for land use change. The paper also fills in an important void in the literature by letting land operators provide a ranking of factors that affect land use conversion in the eastern Dakotas. We give evidence that changing crop prices, changing prices in input markets, improved crop yields and more efficient cropping equipment are among the most important motives for changing land use. Not surprisingly, prices are reported to be the most important factors. Among the ten issues we listed, wildlife habitat improvement is found to be the least important. It noteworthy that that in many instances spatial direction variables provide intuitively consistent explanations of the varied importance of prices and policies, technology innovations, climate and wildlife in different regions. This is true even though some of the effects are nuanced and only indirect information are available on these variables in the form of producer motivations for land use change.

\section{Acknowledgements}

We thank USDA NIFA for their financial support of this research project titled "Adaptation of Agroecosystems to Climate Change at the Edge of the US Cornbelt-Assessing Different drivers in a Network of Infrastructure", DUNS No. 005309844. We also thank the respondents for sharing their information and viewpoints. Many individuals provided insightful reviews on the 
original questionnaire, including Mr. Carter Anderson, who was State Statistician in South Dakota for USDA-NASS (National Agricultural Statistics Service) in South Dakota during the time of questionnaire development. 


\section{References}

Arora, G., Wolter, P.T., Feng, H., Hennessy, D.A., 2016. Role of ethanol plants in Dakotas land use change: Incorporating flexible trends in difference-in-difference framework with remotely-sensed data. Center for Agricultural and Rural Development Working Paper 16-WP 564, March, http://www.card.iastate.edu/publications/synopsis.aspx?id=1250.

Babcock, B.A., Hart, C.E., 2004. Risk-free farming. Iowa Ag Review 10(1), Article 1, available at: http://ib.dr.iastate.edu/iowaagreview/vol10/iss1/1

Bills, N.L., 1985. Cropland Rental and Soil Conservation in the United States. AER-529. U.S. Department of Agriculture, Economics Resource Service.

Claassen R., Cooper, J.C., Carriazo, F., 2011a. Crop insurance, disaster payments, and land use change: The effects of Sodsaver on incentives for grassland conversion. Journal of Agricultural and Applied Economics 43(2), 195-211.

Claassen R., Carriazo, F., Cooper, J.C., Hellerstein, D., Ueda, K., 2011b. Grassland to Cropland Conversion in the Northern Plains: The Role of Crop Insurance, Commodity, and Disaster Programs. Economic Research Report No. ERR-120 (US Department of Agriculture Economic Research Service, Washington, DC.

Clay, D.E., Clay, S.A., Reitsma, K.D., Dunn, B.H., Smart, A.J., Carlson, G.G., Horvath, D., Stone, J.J., 2014. Does the conversion of grasslands to row crop production in semiarid areas threaten global food security? Global Food Security3(1), 22-30.

Cooke, B., Moon, K., 2015. Aligning 'public good' environmental stewardship with the landscape-scale: Adapting MBIs for private land conservation policy. Ecological 
Economics 114, 152-158.

Eve, M.D., Sperow, M., Howerton, K., Paustian, K., Follett, R.F., 2002. Predicted impact of changes on soil carbon storage for each cropland region of the conterminous United States. Journal of Soil and Water Conservation 57(4), 196-204.

Faber, S., Rundquist, S., Male, T., 2012. Plowed Under: How Crop Subsidies Contribute to Massive Habitat Losses. Environmental Working Group, Washington DC.

Feder, G., Just, R.E., Zilberman, D., 1985. Adoption of agricultural innovations in developing countries: A survey. Economic Development and Cultural Change 33(2), 255-298.

Feng, H., Hennessy, D.A., Miao, R., 2013. The effects of government payments on cropland acreage, conservation reserve program enrollment, and grassland conversion in the Dakotas. American Journal of Agricultural Economics 95(2), 412418.

Gascoigne, W.R., Hoag, D., Koontz, L., Tangen, B.A., Shafer, T.L., Gleason, R.A., 2011. Valuing ecosystem and economic services across land-use scenarios in the Prairie Pothole Region of the Dakotas, USA. Ecological Economics 70, 1715-1725.

Gelfand, I., Zenone, T., Jasrotia, P., Chen, J., Hamilton, S.K., Robertson, G.P., 2011. Carbon debt of Conservation Reserve Program (CRP) grasslands converted to bioenergy production. Proceedings of the National Academies of Sciences USA 108(33), 13,86413,869 .

Hardy Vincent, C., Hanson, L.A., Bjelopera, J.P., 2014. Federal land ownership: Overview and data. Congressional Research Service Report for Congress 7-5700. Washington 
DC, USA.

Hoppe, R.A., Green, R., Wunderlich, G., 1995. Farmland rentals: Central to farming.

Agricultural Outlook AO-220. Economic Research Service.

Huffman, W.E., Mercier, S., 1991. Joint adoption of microcomputer technologies: An

analysis of farmers' decisions. Review of Economics and Statistics 73(3), 541-546.

Huffman W., Evenson, R., 1993. Science for Agriculture: A Long-Term Perspective. Iowa State University Press, Ames, Iowa (p. 163).

Jacoby, H.G., Mansuri, G., 2008. Land tenancy and non-contractible investment in rural

Pakistan. Review of Economic Studies 75(3), 763-788.

Janssen, L., Davis, J., Inkoom, S.A., 2015. South Dakota Agriculture Land Market Trends

1991-2015. South Dakota State University Publication 03-7008-2015.

https://igrow.org/up/resources/03-7008-2015.pdf, last accessed October 26, 2016.

Job Service North Dakota, 2014. North Dakota Workforce Review. Labor Market

Information Center. Retrieved from

https://www.doleta.gov/Performance/Results/AnnualReports/2013_economic_reports/

ND_PY13_Workforce_Review_2014.pdf, October 26, 2016.

Johnson, D.H., 2000. Management of Northern Prairies and Wetlands for the

Conservation of Neotropical Migratory Birds. In: F.R. Thompson, III, ed.,

Management of Midwestern Landscapes for the Conservation of Neotropical

Migratory Birds. St. Paul, MN: U.S. Department of Agriculture, Forest Service, North-

Central Experiment Station, General Technical Report NC-187, November, pp. 53-67.

Kahneman, D., 2011. Thinking, Fast and Slow. Farrar, Straus and Giroux, New York. 
Lark, T.J., Salmon, J.M., Gibbs, H.K., 2015. Cropland expansion outpaces agricultural and biofuel policies in the United States. Environmental Research Letters 10(4), 044003.

Lee, S., D.E. Clay, and S.A. Clay., 2014. Conservation tillage and genetically modified herbicide tolerant corn (Zea mays), soybean (Glycine max), and cotton (Gossypium hirsutum): Adoption linked impacts on the environment and economic returns. In: D.D. Songstad, J.L. Hatfield and D.T. Tomes, eds., Convergence of Food Security, Energy Security and Sustainable Agriculture. Springer-Verlag, Berlin, pp. 211-236. Lichtenberg, E., 2007. Tenants, landlords, and soil conservation. American Journal of Agricultural Economics 89(2), 294-307.

Lindstrom, M.J., Schumacher, T.E., Blecha, M.L., 1994. Management consideration for returning CRP land to crop production. Journal of Soil and Water Conservation 49(5), 420-425.

Lipsey, M.K., Doherty, K.E., Naugle, D.E., Fields, S., Evans, J.S., Davis, S.K., Koper, N., 2015. One step ahead of the plow: Using cropland conversion risk to guide Sprague's Pipit conservation in the Northern Great Plains. Biological Conservation 191, 739749 .

Luri, M., 2015. Drivers of agricultural land use change and management decisions in the Dakotas: the influence of climate and other factors. M.S. Thesis, South Dakota State University, Brookings, MI, 268 pages.

McFadden, D., 1974. The measurement of urban travel. Journal of Public Economics 3(4), 303-328.

MEA, 2005. Millenium ecosystem assessment. In Ecosystems and human well-being: 
biodiversity synthesis. Washington, DC: World Resources Institute.

Meehan, T.D., Werling, B.P., Landis D.A., Gratton, C. 2011. Agricultural landscape simplification and insecticide use in the Midwestern United States. Proceedings of the National Academy of Sciences 108, 11500-5

Meehan, T.D., Gratton, C. 2015. A consistent positive association between landscape simplification and insecticide use across the Midwestern US from 1997 through 2012. Environmental Research Letters 10(11), 114001.

Miao, R., Hennessy, D.A., Feng, H., 2014. Sodbusting, crop insurance, and sunk conversion. Land Economics 90(4), 601-622.

Miao, R., Hennessy, D.A., Feng, H., 2016. The effects of crop insurance subsidies and sodsaver on land use change. Journal of Agricultural and Resource Economics 41(2), 247-265.

Motamed, M., McPhail, L., Williams, R., 2016. Corn area response to local ethanol markets in the United States: A grid cell level analysis. American Journal of Agricultural Economics 98(3), 726-743.

National Climate Assessment, 2014. Climate Change Impacts in the United States. Retrieved from http://nca2014.globalchange.gov/, last accessed October 26, 2016.

Nickerson, C., Morehart, M., Kuethe, T., Beckman, J., Ifft, J., Williams, R., 2012. Trends in U.S. Farmland values and ownership. Economic Information Bulletin No. 92, USDA Econ Res. Serv., Washington, DC, http://www.ers.usda.gov/media/377487/eib92_2_.pdf. Perry, E., Moschini, G., Hennessy, D.A., 2016. Testing for complementarity: Glyphosate tolerant soybeans and conservation tillage. American Journal of Agricultural 
Economics 98(3), 765-784.

Pimentel, D., Harvey C., Resosudarmo, P., Sinclair, K., Kurz, D., McNair, M., Crist, S., Shpritz, L., Fitton, R., Saffouri, R., Blair, R., 1995. Environmental and economic costs of soil erosion and conservation benefits. Science 267(5201), 1117-1123.

Rashford, B.S., Walker, J.A., Bastian, C.T., 2010. Economics of grassland conversion to cropland in the Prairie Pothole region. Conservation Biology 25(2), 276-284.

Reitsma, K.D., Dunn, B.H., Mishra, U., Clay, S.A., DeSutter, T., Clay, D.E., 2015. Land use change impact on soil sustainability in a climate and vegetation transition zone. Agronomy Journal 107(6), 2363-2372.

Reilly, J., Tubiello F., McCarl B., Abler D., Darwin R., Fuglie K., Hollinger S., Izaurralde C., Jagtap S., Jones J., Learns L., Ojima D., Paul E., Paustian K., Riha S., Rosenberg N., and Rosenzweig C., 2003: U.S. agriculture and climate change: New results. Climatic Change 57, 43-69.

Rosenberg, N.J., 1992. Adaptation of agriculture to climatic change. Climatic Change 21(4), 385-405.

Soule, M.J., Tegene, A., Wiebe, K.D., 2000. Land tenure and the adoption of conservation practices. American Journal of Agricultural Economics 82(4), 993-1005.

Swengel, A.B., Swengel, S.R., 2015. Grass-skipper (Hesperiinae) trends in Midwestern USA grasslands during 1988-2013. Journal of Insect Conservation 19(2), 279-292. Travers, S.E., Marquardt, B., Zerr, N.J., Finch, J.B., Boche, M.J., Wilk, R., Burdick, S.C., 2015. Climate change and shifting arrival date of migratory birds over a century in the northern Great Plains. Wilson Journal of Ornithology 127(1), 43-51. 
U.S. Government Accountability Office (USGAO), 2007. Agricultural Conservation: Farm Program Payments Are an Important Factor in Landowners' Decisions to Convert Grassland to Cropland. Washington, D.C., Report 07-1054, September, 70 pages.

Varble, S., Secchi, S., Druschke, C.G., 2016. An examination of growing trends in land tenure and conservation practice adoption: Results from a farmer survey in Iowa. Environmental Management 56(2), 318-330.

Walker, J., Rotella, J.J., Loesch, C.R., Renner, R.W., Ringelman, J.K., Lindberg, M.S., Dell, R., Doherty, K.E., 2013. An integrated strategy for grassland easement acquisition in the Prairie Pothole Region, USA. Journal of Fish and Wildlife Management 4(2), 267279.

Withey, P., van Kooten, G.C., 2011. The effects of climate change on optimal wetland and waterfowl management in Western Canada. Ecological Economics 70, 798-805.

Wright, C.K., Wimberly, M.C., 2013. Recent land use change in the Western Corn Belt threatens grasslands and wetlands. Proceedings of the National Academies of Sciences USA 110(10), 4134-4139.

Zepeda, L., 1990. Predicting bovine somatotropin use by California dairy farmers. Western Journal of Agricultural Economics 15(1), 55-62. 
Table 1. Definition of different variables.

\begin{tabular}{|c|c|c|}
\hline & Variable & Description \\
\hline \multirow{4}{*}{$\begin{array}{l}\text { Prices and } \\
\text { Policy }\end{array}$} & $Y_{1}$ & Changing crop prices \\
\hline & $Y_{2}$ & $\begin{array}{l}\text { Changing input market prices (seed, fertilizer, } \\
\text { chemicals, etc.) }\end{array}$ \\
\hline & $Y_{3}$ & Availability of crop insurance policies \\
\hline & $Y_{4}$ & Labor availability problems \\
\hline \multirow[t]{4}{*}{ Technology } & $Y_{5}$ & Availability of drought-tolerant seed \\
\hline & $Y_{6}$ & $\begin{array}{l}\text { Development in pest management practices, including } \\
\text { seed traits }\end{array}$ \\
\hline & $Y_{7}$ & Improved crop yields \\
\hline & $Y_{8}$ & Development of more efficient cropping equipment \\
\hline \multirow[t]{2}{*}{ Environmental } & $Y_{9}$ & Improving wildlife habitat \\
\hline & $Y_{10}$ & Changing weather/climate patterns \\
\hline \multicolumn{2}{|c|}{$\% \mathrm{LCC}=4,1$ mile radius } & $\begin{array}{l}\% \text { soils with Land Capability Class (LCC) equal to IV } \\
\text { within } 1 \text { mile radius }\end{array}$ \\
\hline \multicolumn{2}{|c|}{$\%$ slope $\leq 3,1$ mile radius } & $\begin{array}{l}\% \text { soils with SLOPE no more than } 3 \text { within } 1 \text { mile } \\
\text { radius }\end{array}$ \\
\hline
\end{tabular}


Table 2. Descriptive statistics for the motive variables.

\begin{tabular}{|c|c|c|c|c|c|c|}
\hline & Variab & $\mathrm{N}$ & Mean & Std. Dev. & $\begin{array}{r}\text { Minimu } \\
\mathrm{m}\end{array}$ & $\begin{array}{r}\text { Maximu } \\
\mathrm{m}\end{array}$ \\
\hline \multirow[t]{4}{*}{$\begin{array}{l}\text { Prices and } \\
\text { Policy }\end{array}$} & $Y_{1}$ & 1,010 & 2.190 & 0.839 & 1 & 3 \\
\hline & $Y_{2}$ & 1,002 & 2.079 & 0.823 & 1 & 3 \\
\hline & $Y_{3}$ & 1,003 & 1.788 & 0.813 & 1 & 3 \\
\hline & $Y_{4}$ & 1,004 & 1.514 & 0.748 & 1 & 3 \\
\hline \multirow[t]{4}{*}{ Technology } & $Y_{5}$ & 1,004 & 1.606 & 0.763 & 1 & 3 \\
\hline & $Y_{6}$ & 1,003 & 1.838 & 0.800 & 1 & 3 \\
\hline & $Y_{7}$ & 1,006 & 2.114 & 0.795 & 1 & 3 \\
\hline & $Y_{8}$ & 1,006 & 1.941 & 0.833 & 1 & 3 \\
\hline \multirow[t]{2}{*}{$\begin{array}{l}\text { Environmental } \\
\text { concerns }\end{array}$} & $Y_{9}$ & 1,002 & 1.416 & 0.657 & 1 & 3 \\
\hline & $Y_{10}$ & 1,007 & 1.766 & 0.810 & 1 & 3 \\
\hline \multicolumn{2}{|l|}{ Crop percentage } & 948 & 0.740 & 0.280 & 0 & 1 \\
\hline \multicolumn{2}{|c|}{$\% \mathrm{LCC}=4,1$ mile radius } & 1,025 & 3.000 & 13.123 & 0 & 100 \\
\hline \multicolumn{2}{|c|}{$\%$ slope $\leq 3,1$ mile radius } & 1,025 & 48.082 & 44.502 & 0 & 100 \\
\hline \multicolumn{2}{|c|}{ Farm size (1,000 acre) } & 996 & 1.686 & 1.937 & 0.018 & 27 \\
\hline \multicolumn{2}{|l|}{ ownership } & 1,001 & 2.752 & 1.220 & 1 & 5 \\
\hline \multicolumn{2}{|l|}{ Farmer age } & 1,017 & 3.303 & 1.084 & 1 & 5 \\
\hline \multicolumn{2}{|l|}{ Latitude } & 1,025 & $45.273 \mathrm{~N}$ & 1.288 & 42.91 & 47.83 \\
\hline \multicolumn{2}{|l|}{ Longitude } & 1,025 & $98.023 \mathrm{~W}$ & 1.043 & 96.47 & 100.79 \\
\hline
\end{tabular}

Note: For Q10a, '1', '2' and '3' indicate low, medium and high impact, respectively. 
Table 3. Ordered logit model regression results on price and policy queries.

\begin{tabular}{lrrrr}
\hline Variables & Crop prices, & Input prices, $Y_{2}$ & Insurance policies, $Y_{3}$ & Labor availability, $Y_{4}$ \\
\hline Intercept 3 & $Y_{1}$ & & -1.467 & $-16.235^{* *}$ \\
Intercept 2 & $-13.533^{* * *}$ & -6.891 & -0.157 & $-15.063^{* *}$ \\
\% LCC = 4, 1 mile radius & $-12.340^{* *}$ & -5.497 & -0.004 \\
\% slope $\leq$ 3, 1 mile radius & -0.006 & 0.001 & 0.006 & -0.002 \\
Farm size (1,000 acres) & $0.003^{* * *}$ & 0.001 & $0.004^{* * *}$ & $0.140^{* * *}$ \\
Tenancy index & 0.008 & -0.028 & $0.081^{* *}$ & 0.026 \\
Age & $0.126^{* * *}$ & $0.129^{* *}$ & 0.058 & $-0.119^{*}$ \\
Latitude & $-0.224^{* * *}$ & $-0.190^{* * *}$ & -0.036 & $0.190^{* * *}$ \\
Longitude & $0.262^{* * *}$ & $0.214^{* * *}$ & 0.052 & 0.062 \\
\hline Percent Concordant & 0.018 & -0.031 & -0.025 & 62.0 \\
\hline
\end{tabular}

Note: One, two and three stars represent, respectively, $10 \%, 5 \%$ and $1 \%$ levels of statistical significance. 
Table 4. Ordered logit model regression results on technology queries.

\begin{tabular}{|c|c|c|c|c|}
\hline Variables & $\begin{array}{r}\text { Drought } \\
\text { tolerant seed, } \\
Y_{5}\end{array}$ & $\begin{array}{r}\text { Pest management } \\
\text { practices, } Y_{6}\end{array}$ & $\begin{array}{r}\text { Improved crop } \\
\text { yields, } Y_{7}\end{array}$ & $\begin{array}{r}\text { More efficient } \\
\text { cropping equipment, } \\
Y_{8}\end{array}$ \\
\hline Intercept 3 & -7.252 & $19.868^{* * *}$ & 0.699 & $-11.346^{*}$ \\
\hline Intercept 2 & -5.906 & $21.343^{* * *}$ & 2.260 & -10.001 \\
\hline $\begin{array}{l}\% \mathrm{LCC}=4,1 \text { mile } \\
\text { radius }\end{array}$ & $-0.010^{*}$ & 0.001 & -0.002 & -0.003 \\
\hline $\begin{array}{l}\% \text { slope } \leq 3,1 \text { mile } \\
\text { radius }\end{array}$ & 0.000 & 0.000 & 0.002 & 0.000 \\
\hline Farm size (1,000 acres) & 0.043 & $0.079^{* *}$ & $0.105^{* * *}$ & $0.230^{* * * *}$ \\
\hline Tenancy index & 0.053 & 0.069 & 0.027 & 0.037 \\
\hline Age & 0.088 & 0.093 & -0.095 & -0.052 \\
\hline Latitude & $-0.173^{* * *}$ & -0.070 & 0.066 & $0.117^{* *}$ \\
\hline Longitude & $0.133^{* *}$ & $-0.188^{* * *}$ & -0.043 & 0.051 \\
\hline Percent Concordant & 57.5 & 56.8 & 56.9 & 61.5 \\
\hline
\end{tabular}

Note: One, two and three stars represent, respectively, $10 \%, 5 \%$ and $1 \%$ levels of statistical significance. 
Table 5. Ordered logit model regression results on environment queries.

\begin{tabular}{lrr}
\hline Variables & Improving wildlife habitat, & Changing weather/climate \\
& $Y_{9}$ & patterns, $Y_{10}$ \\
\hline Intercept 3 & $-13.430^{*}$ & -13.162 \\
Intercept 2 & $-11.876^{*}$ & -11.832 \\
\% LCC = 4, 1 mile radius & 0.002 & 0.004 \\
\% slope $\leq$ 3, 1 mile radius & 0.000 & $0.003^{* *}$ \\
Farm size (1,000 acres) & -0.004 & -0.001 \\
Tenancy index & 0.022 & 0.076 \\
Age & -0.042 & -0.051 \\
Latitude & -0.072 & $0.179^{* * *}$ \\
Longitude & $0.148^{* *}$ & 0.037 \\
\hline Percent Concordant & 53.2 & 58.2 \\
\hline
\end{tabular}

Note: One, two and three stars represent, respectively, $10 \%, 5 \%$ and $1 \%$ levels of statistical significance. 
Table 6. Responses and hypotheses.

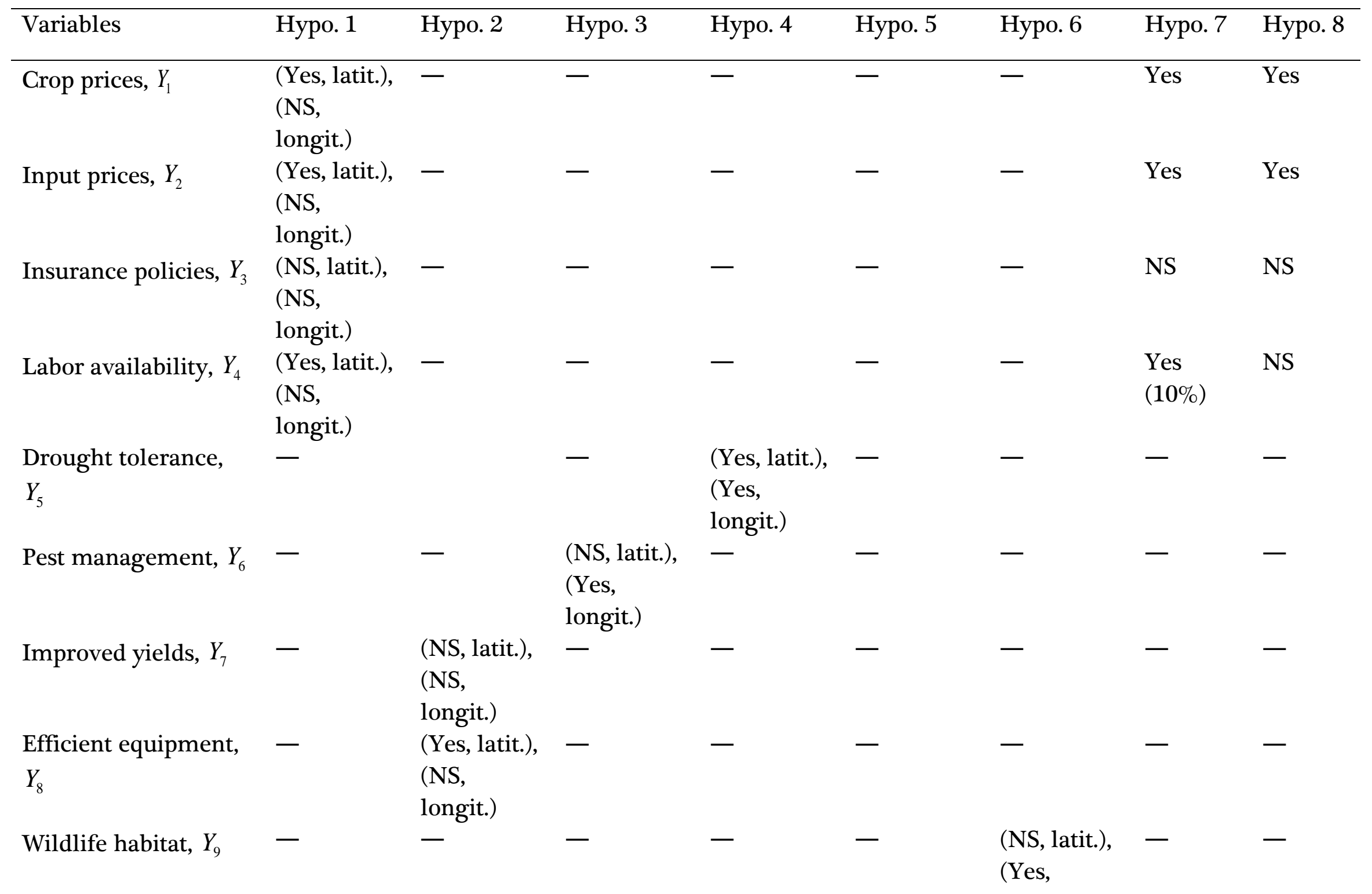




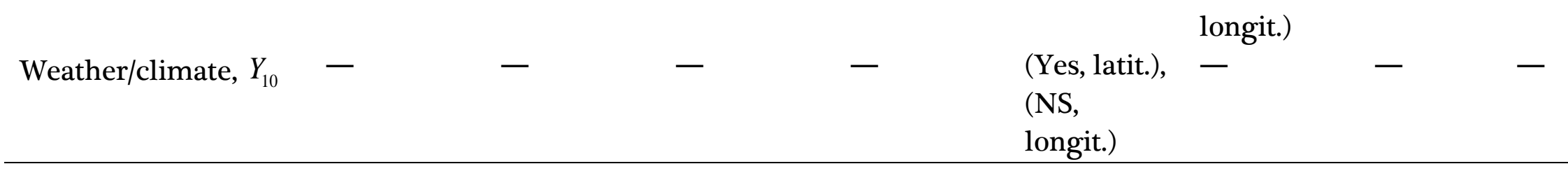

Notes: 'latit.' denotes latitude while 'longit.' denotes longitude. 'Yes' indicates that sign is consistent with hypothesis and has significance $5 \%$ or lower. 'Yes $(10 \%)$ ' indicates that sign is consistent with hypothesis and has significance greater than $5 \%$ but no more than $10 \%$. 'NS' indicates that it is not significant in either direction. 


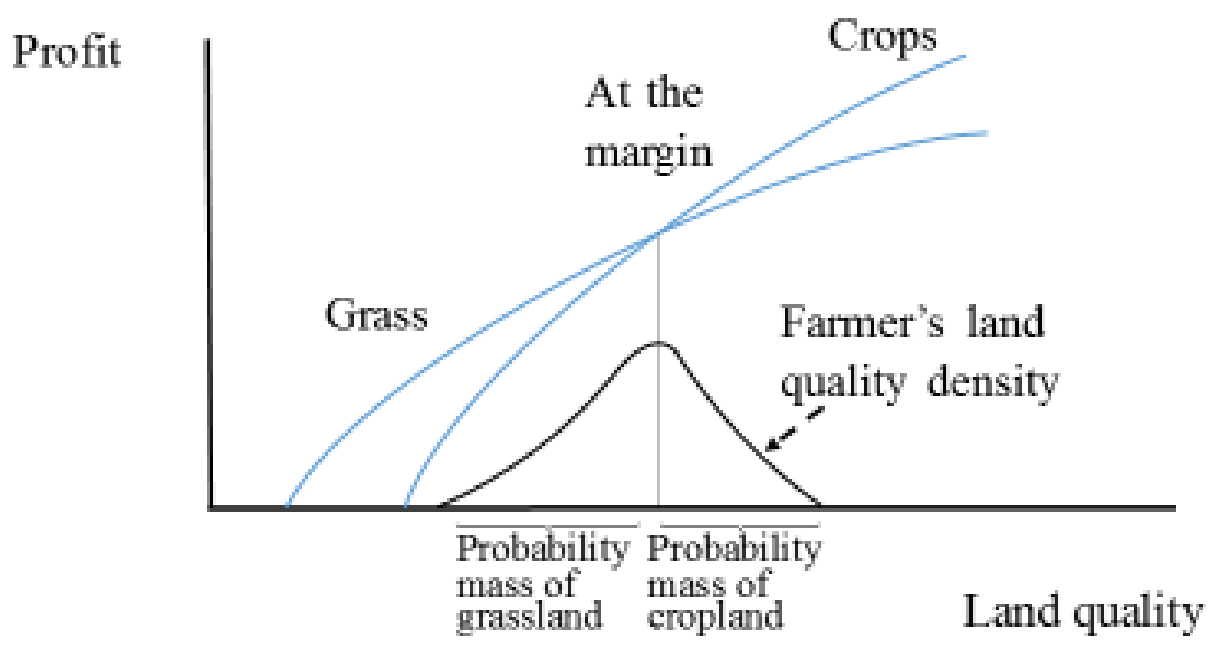

Figure 1. Land switching between grass and cropping uses.

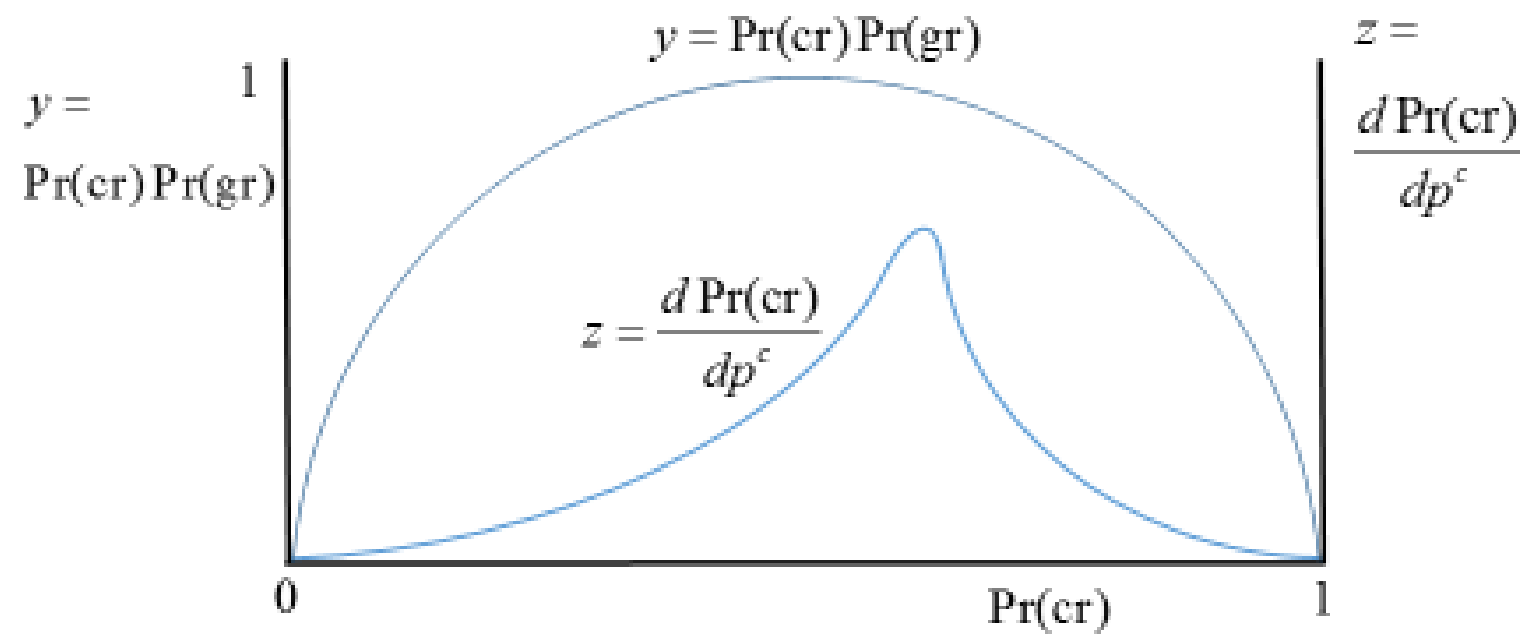

Figure 2. Cropping probability/share responsiveness to output price. 


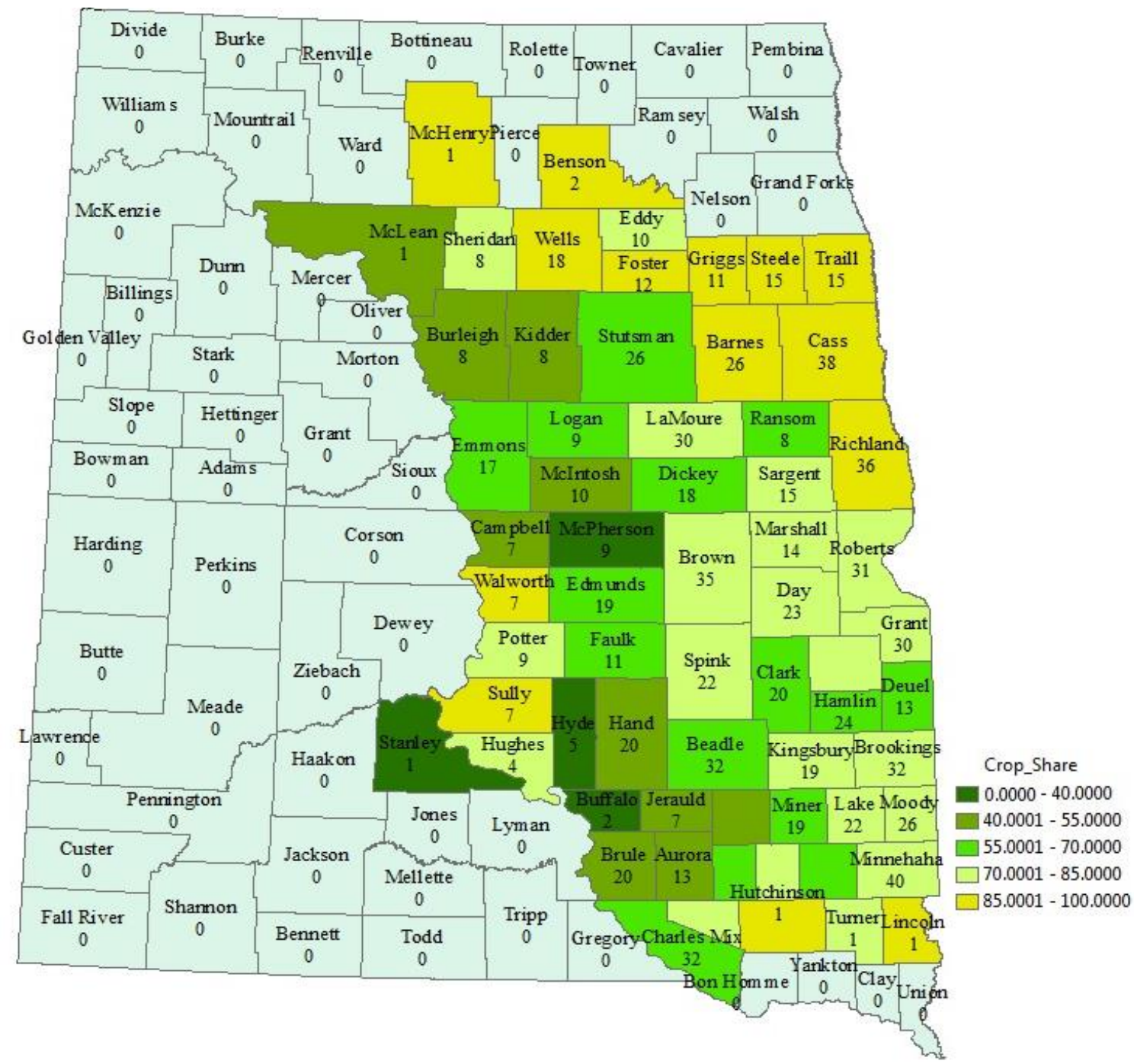

Figure 3. Cropland as a share of respondent acres. Yellow represents $85-100 \%$ of average operator acres under cultivated crops. Dark green represents no more than $40 \%$ of operator acres under cultivated crops. Light green represents intermediate levels of operator acres under cultivated crops. Note, county names and survey respondent numbers are provided where these can be included. 


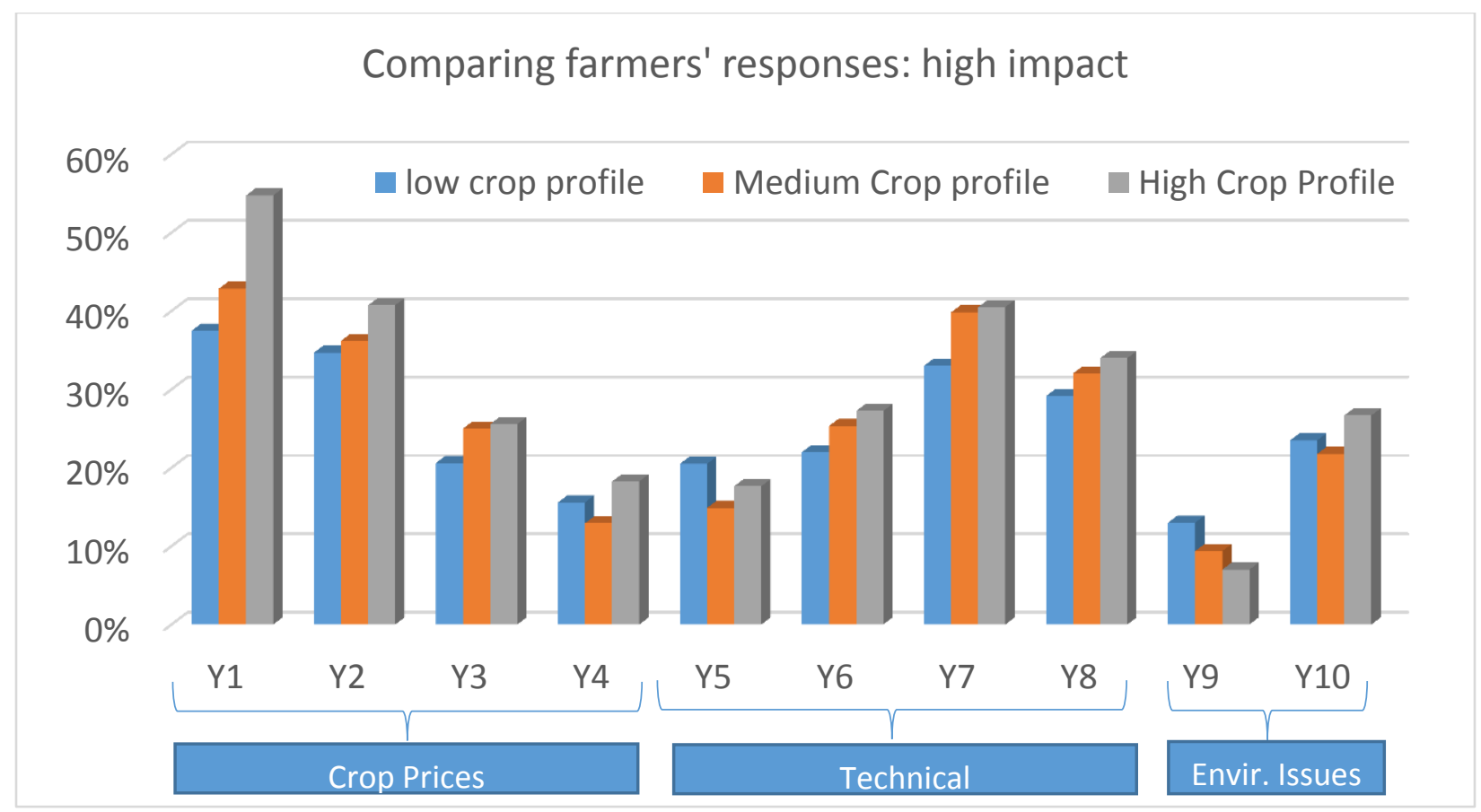

Figure 4 (a). Percentage of high impact choice $\left(Y_{i}=3, i \in\{1, \cdots, 10\}\right)$ for farmers with 3 different profiles: low crop profile (crop percentage below $50 \%$ ), medium crop profile (crop percentage between 50\% and 90\%) and high crop profile farmers (crop percentage above $90 \%)$. 


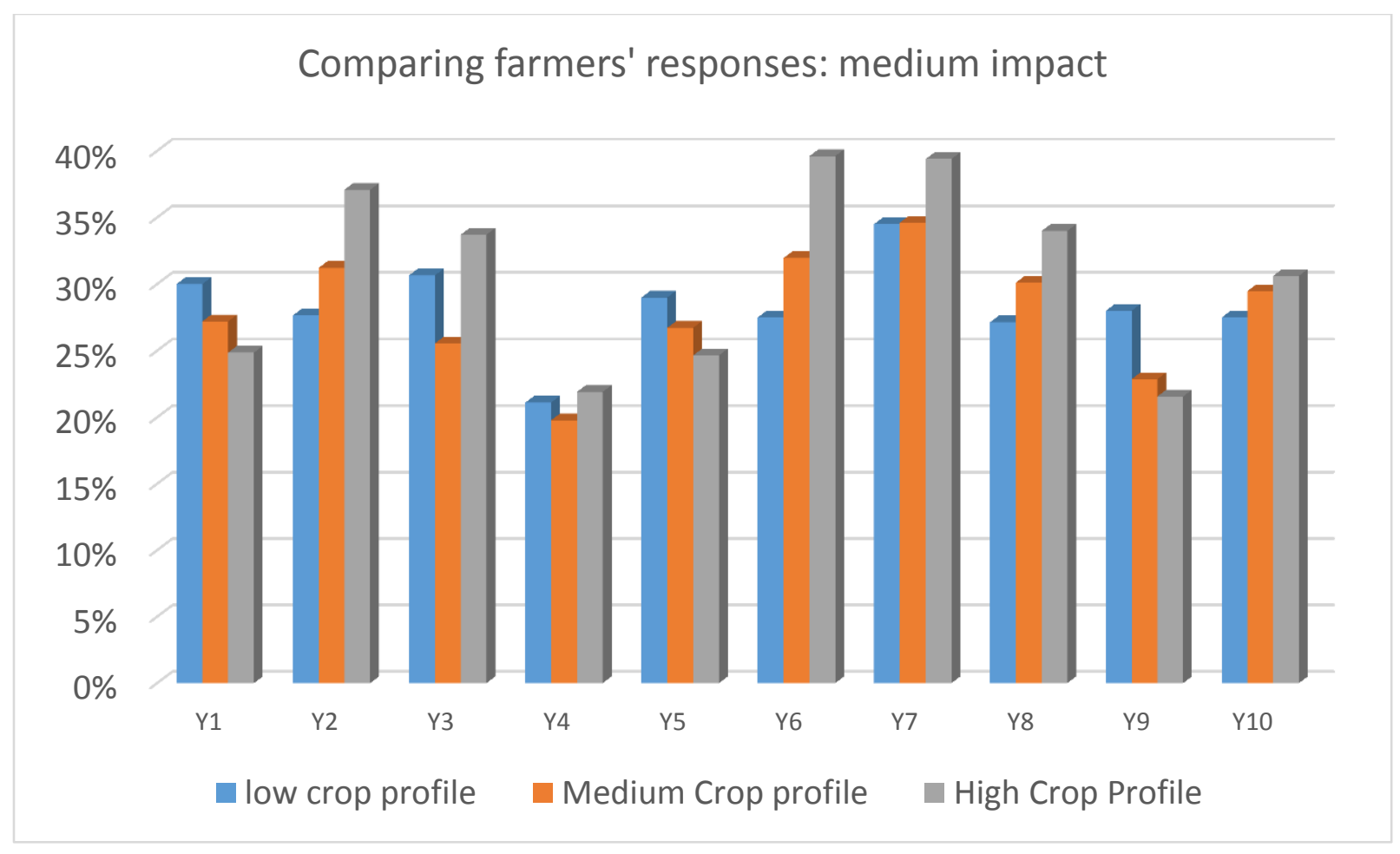

Figure 4 (b). Percentage of medium impact choice $\left(Y_{i}=2, i \in\{1, \cdots, 10\}\right)$ for farmers with 3 different profiles: low crop profile (crop percentage below 50\%), medium crop profile (crop percentage between 50\% and 90\%) and high crop profile farmers (crop percentage above $90 \%)$. 


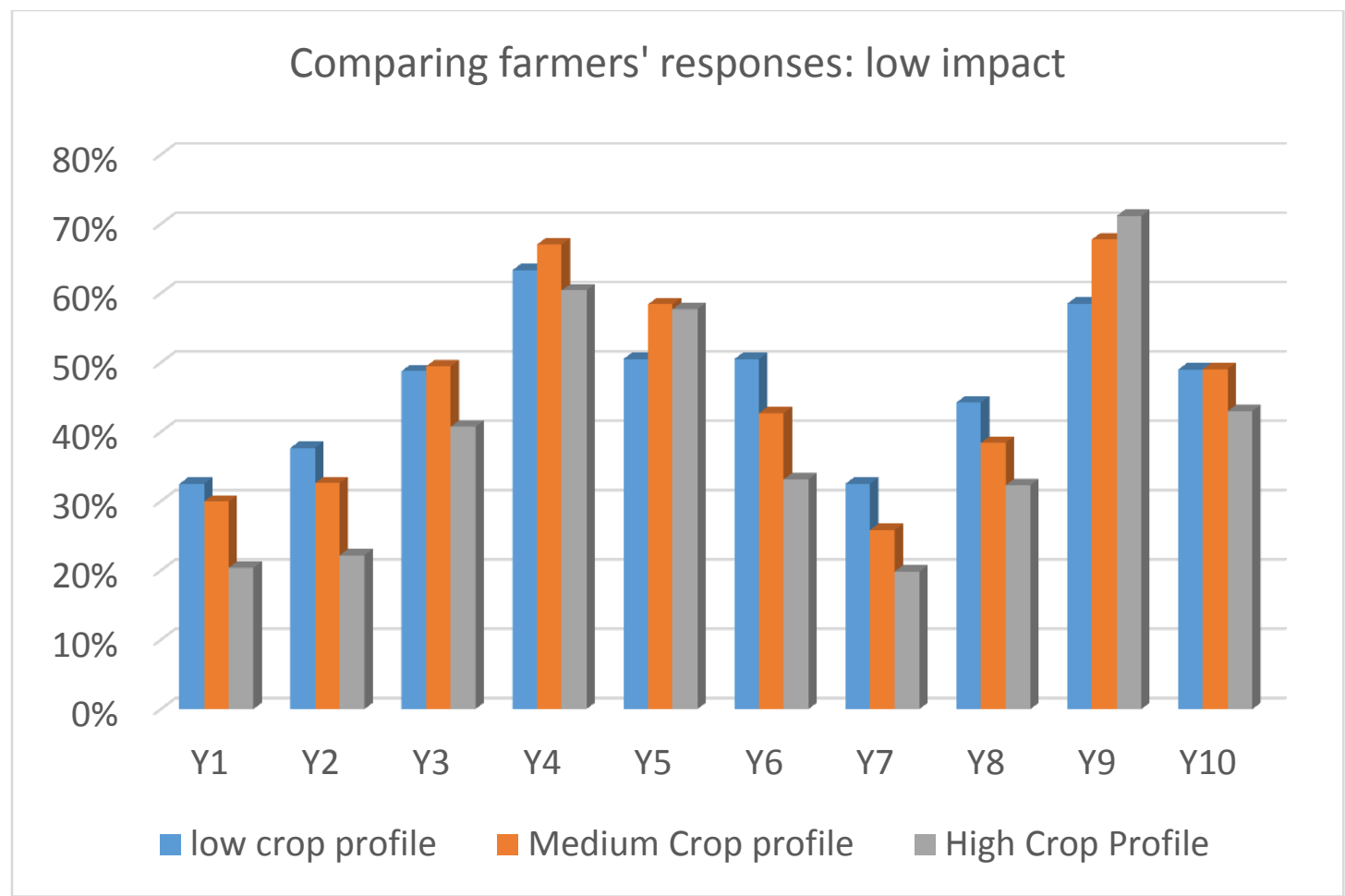

Figure 4 (c). Percentage of low impact choice $\left(Y_{i}=1, i \in\{1, \cdots, 10\}\right)$ for farmers with 3 different profiles: low crop profile (crop percentage below 50\%), medium crop profile (crop percentage between $50 \%$ and $90 \%$ ) and high crop profile farmers (crop percentage above $90 \%$ ). 